\title{
Treatment fidelity in the Camden Weight Loss (CAMWEL) intervention assessed from recordings of advisor-participant consultations
}

\author{
Lorraine M Noble ${ }^{1 *}$ D, Emma Godfrey², Liane Al-Baba ${ }^{3}$, Gabriella Baez ${ }^{2}$, Nicki Thorogood ${ }^{4}$ and Kiran Nanchahal ${ }^{4}$
}

\begin{abstract}
Background: Variations in the delivery of content and process can alter the effectiveness of complex interventions. This study examined the fidelity of a weight loss intervention (Camden Weight Loss) from recorded consultations by assessing advisors' delivery of content, use of motivational interviewing approach and therapeutic alliance.

Methods: A process evaluation was conducted of advisor-participant consultations in a 12-month randomised controlled trial of an intervention for adult volunteers with a body mass index categorised as overweight or obese. A convenience sample of 22 consultations (12\% of 191 participants) recorded at the intervention mid-point were available for analysis. Consultations were independently rated by two observers independent of intervention or study delivery, using: a fidelity scale, the Motivational Interviewing Treatment Integrity Scale and the Primary Care Therapy Process Rating Scale. Raters were blind to participants' responses to the intervention and weight outcomes. Half the participants $(N=11)$ achieved significant weight loss ( $\geq 5 \%$ of baseline weight).

Results: A mean of $41 \%$ of prescribed content was delivered, with a range covered per session of 8-98\%, falling below the 100\% content expected per session. Tasks included most frequently were: taking weight and waist measurements (98\%), scheduling next appointment (86\%), review of general progress (85\%) and reviewing weight change (84\%). Individual items most frequently addressed were 'giving encouragement' and 'showing appreciation of participant's efforts' (95 and 88\% respectively). Consultation length (mean 19 min, range 9-30) was shorter than the 30-min allocation. Quantity of content correlated with consultation length $(p<0.01)$. Advisors' use of motivational interviewing was rated at 'beginner proficiency' for Global Clinician Rating, Reflection to Question Ratio and Percent Open Questions. Therapeutic alliance scores were moderate. Affective aspects were rated highly (e.g. supportive encouragement, involvement and warmth).
\end{abstract}

Conclusions: Intervention fidelity varied in both content and process, emphasising the importance of ongoing fidelity checks in a complex intervention. Advisors focused on certain practical aspects of the intervention and providing an encouraging interpersonal climate. This concurs with other research findings, which have revealed the value participants in a weight loss intervention place on an empathic advisor-participant relationship.

Clinical trials registration: Registered with Clinicaltrials.gov, number NCT00891943, on 1 May 2009.

Keywords: Obesity, Overweight, Weight loss, Trial, Intervention, Fidelity, Motivational interviewing, Therapeutic alliance, Communication

\footnotetext{
* Correspondence: lorraine.noble@ucl.ac.uk

'UCL Medical School, University College London, Royal Free Hospital,

Rowland Hill Street, NW3 2PF, London, UK

Full list of author information is available at the end of the article
}

(c) The Author(s). 2018 Open Access This article is distributed under the terms of the Creative Commons Attribution 4.0 International License (http://creativecommons.org/licenses/by/4.0/), which permits unrestricted use, distribution, and reproduction in any medium, provided you give appropriate credit to the original author(s) and the source, provide a link to the Creative Commons license, and indicate if changes were made. The Creative Commons Public Domain Dedication waiver (http://creativecommons.org/publicdomain/zero/1.0/) applies to the data made available in this article, unless otherwise stated. 


\section{Background}

The increasing impact of obesity on health has caused international alarm $[1,2]$. It is estimated that 2.8 million people die annually due to overweight or obesity [2]. In the UK, $65 \%$ of men, $58 \%$ of women and $33 \%$ of children aged 10-11 are overweight or obese [3]. Health problems related to obesity are estimated to cost the UK National Health Service $£ 5$ billion per year [4].

Guidance recommends multi-component weight management interventions focusing on dietary intake, physical activity and behaviour change, and that behaviour modification addresses: 'problem solving; goal setting; how to carry out a particular task or activity; planning to provide social support or make changes to the social environment; self-monitoring of weight and behaviours that can affect weight; and feedback on performance' [5]. Affective features of weight management interventions are also highlighted, emphasising empathy, support and encouragement, and a respectful and non-judgemental approach.

Guidance reflects the complexity of evidence about weight management and the theoretical basis for behaviour change [6-12]. Multi-component interventions are superior to single-component interventions and result in greater longer term weight loss than control conditions $[7,8]$. However, intervention success varies, with variation not accounted for by participant characteristics or programme components (such as length, intensity or face-to-face contact). Long term weight loss remains a challenge $[9,12,13]$.

Behaviour change interventions aim to encourage people to self-manage their weight in the long term. Motivational interviewing aims to support this by identifying and enhancing an individual's own motivation and self-efficacy. The health professional employs an empathic, supportive and collaborative approach, emphasising the individual's autonomy and encouraging the person to explore their own reasons for, and ambivalence about, changing the target behaviour [14].

Whilst motivational interviewing is effective in promoting behaviour change, many health professionals are 'generalists', using a variety of approaches rather than a single, 'pure' approach. 'Motivational interviewing-style' approaches, which employ some of the elements (such as empathy) without using the full range of techniques, have been investigated [15]. Weight management programmes including either pure or adapted forms of motivational interviewing improve outcomes relative to traditional behaviour change interventions or control conditions $[16,17]$. However, in primary care consultations with patients who were overweight or obese, low levels of techniques consistent with a motivational interviewing approach were observed, specifically empathy and motivational interviewing 'spirit' [18].
The importance of the quality of the therapeutic relationship on outcomes of behaviour change interventions has also been recognised [19]. Therapeutic alliance includes affective aspects of the professional-patient relationship (such as empathy, rapport and warmth) and instrumental aspects (such as agreement on goals and tasks). Baldwin and colleagues highlighted the impact of therapeutic alliance in weight management outcomes, and noted importance of the professional's contribution to developing this alliance [20].

Weight management interventions require professionals to skilfully select and deliver elements in line with evidence and an individual's needs. The importance of initial training and continuing professional development has been highlighted [5]. Key features to promote fidelity (defined as the degree to which an intervention is delivered as intended) are staff training, supervision and an intervention manual [21]. Failure to implement the intervention as designed can result in a 'Type III error', where study results do not reflect the effects of the planned intervention [22]. Fidelity includes exposure, adherence to content and quality of delivery [21]. It is commonly assessed by trained observers, either live or from recordings $[16,21,23]$. For example, one study of fidelity in a behaviour change intervention for diabetes found that staff training improved motivational interviewing spirit [24].

In a 12-month weight loss intervention trial for obese and overweight volunteers, a third of the intervention group achieved clinically significant weight loss $(5 \%$ or more of their baseline weight) [25]. The present study was designed to examine intervention fidelity, to explore whether differences in intervention delivery may have contributed to variability in intervention group outcome.

\section{Study aim}

To investigate weight loss intervention fidelity through assessing the content and process of advisor-participant consultations. Specifically, to establish whether: (i) intervention topics and activities were delivered as intended; (ii) advisors' consultation style was consistent with approaches to support lifestyle behaviour change, in particular, using a motivational interviewing approach and establishing a therapeutic alliance.

\section{Method \\ Design}

This was an independent evaluation examining fidelity of a multi-component weight loss intervention delivered by health advisors to participants with weight categorised as overweight and obese, in the intervention arm of a pragmatic randomised control trial in primary care. This was a descriptive, observational study, conducting a process evaluation using independent, blind ratings of recorded 
advisor-participant consultations. Fidelity of intervention content (scheduled topics and activities) and process (motivational interviewing and therapeutic alliance) were examined. Recordings were taken from the mid-point of the intervention to: (i) assess the therapeutic relationship that had developed, (ii) reduce the influence of participants' and advisors' awareness of intervention outcome (i.e. final weight change).

\section{Participants}

Participants were adults attending the 12-month Camden Weight Loss programme during a two year research period. Consultations were recorded during a five month period. Written consent was obtained from all participants. Out of 191 participants who received the intervention, 104 audio or video-recordings were obtained for 42 participants during the recording period. Including only participants for whom final weight outcomes were available resulted in 34 participants. Of these, recordings from the three mid-intervention sessions were available for 27 participants. Due to problems with sound quality, recordings from five participants were excluded, resulting in a total sample of 22 participants (12\% of 191$)$.

The 22 participants were 10 women and 12 men, predominantly White British/White Other (17 participants), with a mean age of 53 years (range 26-80 years) and a mean body mass index at baseline of 32.6 (range 25.245.1). At outcome (12 months), 11 had achieved clinically significant weight loss (5\% or more of baseline weight) and 11 had not. The 22 participants did not significantly differ from the other 169 trial participants in the intervention arm for: age, baseline weight, waist or body mass index, or final weight loss, but were more likely to be male $\left(12 / 22\right.$ compared to $\left.42 / 169, \mathrm{Chi}^{2}(1)=8.5, p<0.01\right)$ and to complete more sessions (mean 10.9 compared to 7.4 , $\mathrm{t}(158)=3.5, \mathrm{p}<0.01)$.

\section{The weight loss intervention}

The Camden Weight Loss programme was offered to adults with weight categorised as clinically overweight or obese in primary care practices in a research trial [25]. The trial aimed to develop a locally delivered weight loss intervention, in line with the National Health Service Health Trainers Initiative [26], drawing health advisors from local communities, who are trained to support people in adopting healthier lifestyles by using psychological techniques to promote behaviour change. These techniques include supporting others to: choose a behaviour to change, set 'SMART' goals, plan behaviour change, improve confidence, review behaviour change, and embed behaviour change into their lifestyle [26]. The intervention was devised as a multi-component programme to promote behaviour change in line with National Institute for Health and Care Excellence guidance [27] and based on behaviour change models (Social Cognitive Theory, Goal Setting, Systems Thinking) [28-30]. Baseline and final weight were measured by research staff. The results of the randomised controlled trial of 381 participants, which included the 191 participants in the intervention arm, are published elsewhere [25].

Six advisors with a background in health care or exercise were trained to deliver a structured one-to-one intervention. The recordings included five of the advisors: one nurse, two osteopaths and two qualified personal fitness trainers, one of whom also had training in nutrition (CYQ Central YMCA Qualification Level 3 Award). Each participant was allocated to one advisor and were scheduled to attend 14 sessions, lasting $30 \mathrm{~min}$ per session, over 12 months in a primary care setting. The session length was intended to enable more in-depth discussion of weight management than is possible in a standard National Health Service primary care consultation (10 min), whilst being delivered to participants in their local practice. Sessions 9, 10 and 11 straddled the intervention mid-point (6 months).

Advisors attended two days of training, including:

(i) the intervention design and rationale

(ii) effective behaviour change strategies and principles of motivational interviewing

(iii) simulated practice in setting weight loss goals, talking about weight and behaviour change and addressing difficult issues.

Advisors were given a detailed manual listing the goals and content of each session, including handouts for participants in some sessions, and a 20-page booklet on Helping People Change Behaviour, including worked examples of techniques for: motivational interviewing, agenda setting, assessing importance and confidence, listening and informing. During the intervention, advisors attended additional group meetings, including further training in motivational interviewing techniques, and met with research staff individually to discuss intervention progress and any issues in intervention delivery.

Each consultation included a review of progress, recording and reviewing pedometer counts, taking weight and waist measurements, reviewing weight loss progress, introducing a new topic, goal setting, making an action plan and confirming the next appointment. The review included discussing the participant's experience and success with the previous session's topic. The intervention schedule is shown in Table 1. Sessions were delivered on a regular schedule with tapering frequency: fortnightly for 12 weeks, 3-weekly to 27 weeks, 4-weekly to 35 weeks and a 12-week interval to the last session. Further details of the intervention are published elsewhere [25]. The topics addressed in sessions 9, 10 and 11 were: positive and 
Table 1 CAMWEL weight loss programme sessions

\begin{tabular}{clll}
\hline Session & Week & Topic & Content \\
\hline $\begin{array}{cll}\text { Pre-intervention: baseline measurements by researchers } \\
2\end{array}$ & 0 & Getting started & Eliciting personal reasons for losing weight, commitment \\
to programme & Importance of changing habits permanently \\
3 & 2 & Changing habits & Regular meals, portion sizes, easy food swaps \\
4 & 4 & Healthy eating & Incorporating physical activity into daily lifestyle \\
5 & 6 & Let's get active & Acting on environmental cues \\
6 & 8 & Taking charge of your environment & Making healthy choices, discuss alcohol if appropriate \\
7 & 10 & Eating when out and about & Energy balance equation, and action planning \\
8 & 12 & Tip the calorie balance & Ways to stop negative thoughts \\
9 & 15 & Positive thinking & Slips, and getting back on course \\
10 & 21 & Getting off the slippery slope & Difficult social settings and how to control eating \\
6 month measurements by researchers & & \\
11 & 27 & Staying on course & Identify successes, and how to stay on course \\
12 & 31 & Staying active & Additional physical activity to be added to the routine \\
13 & 35 & Managing stress & How stress can affect weight, how to overcome \\
14 & 47 & Reshaping habits & \\
12 month measurements by researchers & &
\end{tabular}

negative thinking, responding to situations where you might 'slip up', social eating, and staying on course in the long term.

\section{Measures}

\section{Treatment fidelity}

Checklists were devised for the three sessions by itemising the session content from the manual, using the same wording for items repeated across sessions. Eight topics were included in every session: (1) reviewing overall progress, (2) reviewing previous topic and handouts, (3) reviewing pedometer counts and physical activity, (4) taking weight and waist measurements, (5) reviewing weight change, (6) presenting new topic, (7) setting goals, making action plans and assigning home activities, (8) setting date of next appointment. Due to the detail in the manual, the initial checklists contained 41, 40, and 52 items respectively for the three sessions. The final checklist for session 9 is shown in Table 2 as an example.

The checklist was piloted using a scoring key of 0 (not done), 1 (partially done) and 2 (completely done) for most of the items (e.g. 'feedback is given on performance'), with some simple items (e.g. 'waist circumference is measured') assessed on a binary scale of 0 (not done) and 1 (done). However, low frequency and brevity of advisor behaviours observed during piloting indicated that measurement was better suited to assessing the presence of behaviours in comparison to expected content, rather than a combination of presence and quality. The scoring key for all items was converted to a binary scale (done/not done). An additional category ('not recorded') noted where items could not be rated due to poor sound quality. A rater crib sheet specified item content, including strategies or examples the advisors had been encouraged to use.

\section{Motivational interviewing}

The Motivational Interviewing Treatment Integrity Scale [31] assesses adherence to and competence in using motivational interviewing, with good inter-rater reliability reported [32, 33]. Global ratings are made for five dimensions: Evocation, Collaboration, Autonomy/ Support, Direction and Empathy on a 5-point scale, and a summary score: Spirit of Motivational Interviewing. Behaviour counts are made for seven aspects: Giving Information, Closed Questions, Open Questions, Simple Reflections, Complex Reflections, Motivational Interviewing Adherent Behaviours and Motivational Interviewing Non-adherent Behaviours. Further summary scores are also computed.

\section{Therapeutic alliance}

The 14-item Alliance scale of the Primary Care Therapy Process Rating Scale [34] assesses the quality of the professional-patient therapeutic bond in psychological interventions conducted in primary care settings. It was designed for research into treatment fidelity and process-outcome relationships and has good internal consistency (Cronbach's alpha 0.88). Items are scored 
Table 2 Example treatment fidelity checklist: session 9

\begin{tabular}{|c|c|}
\hline Item & Topic \\
\hline \multicolumn{2}{|c|}{ 1. Reviewing overall progress } \\
\hline 1 & Previously set goals or intentions are reviewed \\
\hline 2 & Feedback on performance is given \\
\hline 3 & General encouragement is given \\
\hline
\end{tabular}

5

6

7

8

9

10

11

12

14

15

3. Revie

16

17

18

19

20

Positive Thinking handout is reviewed

The following questions are taken into consideration when reviewing the Positive Thinking handout

-What negative thoughts did you catch yourself thinking?

-When was this (in what situation)?

- Were you able to stop them?

- Did you talk back with positive thoughts?

- How did positive thinking help with eating a healthy diet?

- What about changes to your activity habits?

- Did you manage to go for a 30-min walk every day?

Any barriers are uncovered

Usefulness of the other handouts is reviewed:

- CAMWEL walks handout

- Steps/Walks Chart handout

- Rate Your Plate handout

4. Taking weight and waist measurements

$21 \quad$ Waist circumference is measured

Weight is measured

5. Reviewing weight change

(a) If participant has lost weight they are congratulated OR

(b) If the participant has not lost weight they are helped to develop a plan to address their particular problem

6. Presenting new topic - Avoiding The Slippery Slope of Changing Habits for Life

24

25

26

7. Setting goals, making action plans and assigning home activities

'Slips' are defined in a manner that is relevant to the participant

Advisor discusses what to do after a 'slip' to get the participant back on their feet again

Advisor helps to identify some things or situations when the participant 'slips' from healthy eating and being active

27

28

29

30
Participant is encouraged to continue to get back on track

The following leaflets are given:

\section{- Camden Change4Health Walks}

- Recipe book (British Heart Foundation 'Healthy Meals, Healthy Hearts' or 'Food Should be Fun... And Healthy') Participant is reminded to continue to wear their pedometer and record their steps

8. Confirming date of next appointment 
on a 7-point scale, with anchors at four points (not at all, somewhat, considerably, extensively).

\section{Rater training}

Raters were blind to participants' weight loss outcomes. The raters (LA and GB) practised using consultations not included in the analysis (five for treatment fidelity, 18 for motivational interviewing and 10 for therapeutic alliance) and discussed discrepancies. The raters independently rated consultations in batches of five and reconvened to discuss discrepancies. For motivational interviewing, a third rater (LN) independently rated six consultations and met with the raters to discuss discrepancies. For therapeutic alliance, a third rater (EG) independently rated three consultations and met with raters to discuss discrepancies and provide additional examples of ratings. Raters coded each consultation four times: once for treatment fidelity, twice for motivational interviewing (global ratings followed by behaviour counts) and once for therapeutic alliance.

\section{Results}

Treatment fidelity analysis Inter-rater reliability

Overall and specific agreement, for positive and negative agreement, were calculated for each item [35, 36]. Overall agreement was 0.82 (i.e. for $770 / 937$ decisions, the raters agreed that the item had been done or not done). Items with low inter-rater reliability (defined as agreement in less than $70 \%$ of decisions) or with too many missing (due to issues with sound in the recording) were excluded. The items deleted were: (1) initial items, as advisors did not necessarily start the recording immediately, (2) items that could not be reliably recorded from audio-only recordings, e.g. 'advisor shows acceptance of the participant' (which could have been communicated non-verbally) or 'showing the participant's weight change on a graph', (3) repeated items (e.g. 'reviewing previously set goals or intentions' appeared in two places in the session plan), and (4) items that could not be assessed without knowledge of the participant's perspective (e.g. 'uses analogies that are meaningful to the participant').

The resulting checklists contained 31, 32 and 35 items respectively for the three sessions. In the final versions, the proportion of overall agreement was $0.90(0.88,0.90$ and 0.93 respectively). The proportions of specific agreement were 0.88 for positive agreement and 0.92 for negative agreement.

\section{Fidelity identified from the recordings}

Overall, a mean of $41 \%$ of scheduled content was addressed, with session totals of 39,35 and $49 \%$ respectively (Table 3). The amount of content addressed per participant ranged from 24 to $54 \%$ (SD 10\%).

Table 3 Percentage session content addressed by the advisors

\begin{tabular}{|c|c|c|c|c|}
\hline \multirow[t]{2}{*}{ Content of topics } & \multirow{2}{*}{$\begin{array}{l}\text { Session } 9 \\
N=10\end{array}$} & \multirow{2}{*}{$\begin{array}{l}\text { Session } 10 \\
N=6\end{array}$} & \multirow{2}{*}{$\begin{array}{l}\text { Session } 11 \\
N=6\end{array}$} & \multirow{2}{*}{$\begin{array}{l}\text { Total } \\
N=22\end{array}$} \\
\hline & & & & \\
\hline $\begin{array}{l}\text { 1. Review of general progress } \\
\text { Discussing goals from previous session } \\
\text { General feedback and encouragement } \\
\text { Uncovering barriers }\end{array}$ & $85 \%$ & $71 \%$ & $98 \%$ & $85 \%$ \\
\hline $\begin{array}{l}\text { 2. Review of previous topic and handouts } \\
\text { Participant's use of information from last session (Positive Thinking/Avoiding } \\
\text { the Slippery Slope/Social Eating) } \\
\text { Uncovering barriers } \\
\text { Participant's use of handouts }\end{array}$ & $13 \%$ & $0 \%$ & $3 \%$ & $8 \%$ \\
\hline $\begin{array}{l}\text { 3. Review of pedometer counts and physical activity } \\
\text { Pedometer use and step counts } \\
\text { Appreciation of participant's efforts } \\
\text { Use of handout about walks }\end{array}$ & $42 \%$ & $60 \%$ & $12 \%$ & $39 \%$ \\
\hline 4. Taking weight and waist measurements & $100 \%$ & $100 \%$ & $92 \%{ }^{\mathrm{a}}$ & $98 \%$ \\
\hline 5. Reviewing weight change & $75 \%$ & $83 \%$ & $100 \%$ & $84 \%$ \\
\hline $\begin{array}{l}\text { 6. Presenting new topic } \\
\text { Discussing topic with examples (Avoiding the Slippery Slope, Social Eating, } \\
\text { Staying on Course) }\end{array}$ & $68 \%$ & $21 \%$ & $79 \%$ & $60 \%$ \\
\hline $\begin{array}{l}\text { 7. Setting goals, developing action plans and assigning home activities } \\
\text { Encouragement to keep on track } \\
\text { New information leaflets } \\
\text { Reminder to use pedometer }\end{array}$ & $11 \%$ & $13 \%$ & $39 \%$ & $24 \%$ \\
\hline 8. Setting date of next appointment & $80 \%^{a}$ & $83 \%$ & $100 \%$ & $86 \%$ \\
\hline Totals & $39 \%$ & $35 \%$ & $49 \%$ & $41 \%$ \\
\hline
\end{tabular}

${ }^{\mathrm{a}} 2$ data points missing due to problems with the recording 
Content included most frequently was: taking weight and waist measurements (98\%), setting date of next appointment $(86 \%)$, reviewing general progress $(85 \%)$, and reviewing weight change (84\%). The most frequent items were 'giving encouragement' and 'showing appreciation of participant's efforts' (95\% in reviewing general progress and $88 \%$ in reviewing pedometer counts and physical activity).

Topics with lower or more variable frequency were: reviewing participant's use of the previous session's topic and handouts (8\%), reviewing pedometer use, reviewing step counts and physical activity (excluding the item about appreciation of participant's efforts) (19\%), setting goals, developing action plans and assigning home activities $(24 \%)$, and presenting the new topic, which varied from $21 \%$ for session 10 (Social Eating) to $79 \%$ for session 11 (Staying on Course).

Mean consultation length was 18.9 min (SD 7.6, range 9.0-30.4). Quantity of content correlated with consultation length (Spearman's rho 0.73, $p<0.01$ ).

\section{Motivational interviewing Inter-rater reliability}

For the global dimensions, using the categories described by Cicchetti [37] the intra-class correlation coefficients (two-way random, testing for consistency) were excellent for Direction, fair for Empathy, and poor for Evocation, Collaboration, Autonomy/Support and Spirit of Motivational Interviewing (Table 4).

For the behaviour counts, the intra-class correlation co-efficients showed excellent reliability for Giving Information, Simple Reflections, Complex Reflections and Motivational Interviewing Adherent, good reliability for Closed Questions, fair reliability for Open Questions and poor reliability for Motivational Interviewing Non-adherent.

\section{Motivational interviewing identified from the recordings}

The scale authors suggested that a mean score of 3.5 indicates 'beginning proficiency' and 4.0 indicates 'competency' for the global dimensions [31]. The mean scores for Evocation, Collaboration, Autonomy/Support and Spirit of Motivational Interviewing fell below the threshold for 'beginning proficiency', and Empathy was at 'beginning proficiency' (Table 5). The mean score for Direction was high, indicating that advisors maintained focus on the target topic of weight loss.

Mean total questions asked by the advisors was 4.8 (SD 3.0) and mean total reflections was 5.9 (SD 4.5). Summary scores for the behaviour counts fell between the scale authors' suggested scores for 'beginning proficiency' and 'competency' for Reflection to Question ratio and Percent Open Questions, and below the threshold for 'beginning proficiency' for Percent Complex Reflections and Percent MI-Adherent.

\section{Therapeutic alliance \\ Inter-rater reliability and internal consistency}

Excellent internal consistency was found (Cronbach's alpha 0.92). Intra-class correlation coefficients (Table 6) showed excellent reliability for two items (warmth and empathy), good reliability for four items (involvement, rapport, client self-discloses thoughts and feelings, and client and therapist agree on the kind of changes to make), fair reliability for five items (supportive encouragement, client expresses emotions, client works actively

Table 4 Motivational interviewing mean scores by rater and inter-rater reliability for global dimensions and behaviour counts

\begin{tabular}{|c|c|c|c|c|c|}
\hline Global dimensions & Rater 1 Mean (SD) & Rater 2 Mean (SD) & $\operatorname{ICC}(2,2)$ & 95\% Cl Lower & 95\% Cl Upper \\
\hline Evocation & $3.2(1.0)$ & $3.5(0.7)$ & 0.34 & -0.58 & 0.73 \\
\hline Collaboration & $3.3(0.9)$ & $3.2(0.6)$ & 0.37 & -0.52 & 0.74 \\
\hline Autonomy/Support & $3.1(0.7)$ & $3.4(0.6)$ & Scale not reliable ${ }^{a}$ & & \\
\hline Direction & $4.2(1.2)$ & $3.8(1.1)$ & 0.83 & 0.59 & 0.93 \\
\hline Empathy & $3.6(0.7)$ & $3.6(0.6)$ & 0.53 & -0.14 & 0.80 \\
\hline Spirit of Motivational Interviewing & $3.2(0.8)$ & $3.3(0.5)$ & 0.33 & -0.62 & 0.72 \\
\hline \multicolumn{6}{|l|}{ Behaviour counts } \\
\hline Giving Information & $12.3(5.5)$ & $9.1(4.1)$ & 0.86 & 0.67 & 0.94 \\
\hline Closed Questions & $3.0(3.0)$ & $2.3(2.6)$ & 0.65 & 0.16 & 0.85 \\
\hline Open Questions & $2.0(1.7)$ & $2.4(1.4)$ & 0.53 & -0.13 & 0.81 \\
\hline Simple Reflections & $5.1(3.9)$ & $5.4(4.4)$ & 0.83 & 0.59 & 0.93 \\
\hline Complex Reflections & $0.9(1.2)$ & $0.4(1.0)$ & 0.63 & 0.11 & 0.85 \\
\hline Motivational Interviewing Adherent & $6.5(4.3)$ & $7.8(5.1)$ & 0.81 & 0.53 & 0.92 \\
\hline Motivational Interviewing Non-adherent & $8.2(6.9)$ & $4.8(3.5)$ & 0.37 & -0.52 & 0.74 \\
\hline
\end{tabular}

aLanders [39] 
Table 5 Motivational interviewing summary scores for behaviour counts and thresholds for proficiency

\begin{tabular}{llll}
\hline Summary score & Mean (SD) & \multicolumn{2}{l}{ Thresholds for proficiency from Moyers et al. 2010 } \\
\cline { 3 - 4 } & & Beginning proficiency & Competency \\
\hline Reflection to Question ratio & $1.8 \%(2.3)$ & $1 \%$ & $70 \%$ \\
Percent Open Questions & $54.6 \%(27.4)$ & $50 \%$ & $50 \%$ \\
Percent Complex Reflections & $9.3 \%(9.2)$ & $40 \%$ & $100 \%$ \\
Percent Motivational Interviewing Adherent & $53.1 \%(17.2)$ & $90 \%$ & $70 \%$ \\
\hline
\end{tabular}

with therapist's comments, client and therapist share same sense about how to proceed, and client and therapist agree on salient themes), and poor reliability for the remaining three items.

\section{Therapeutic alliance identified from the recordings}

Mean total score was 4.1 (SD 0.8) indicating that the consultations were being rated around the mid-point, between the anchor points of 'somewhat' and 'considerably'. Of the 11 items with fair to excellent reliability, items with a mean score above the mid-point were: supportive encouragement (mean 5.0, SD 1.3), involvement (mean 4.8, SD 1.1), warmth (mean 4.7, SD 1.2), client self-discloses thoughts and feelings (mean 4.5, SD 1.5), rapport (mean 4.4, SD 1.3) and empathy (mean 4.2, SD 1.3).

\section{Relationship of process measures to weight outcome}

Using independent t-tests to compare the 11 participants who had lost $5 \%$ or more of their baseline weight with the 11 participants who had not, there was no difference between the groups for: (i) consultation length, (ii) percentage of total content covered, (iii) motivational interviewing: Motivational Interviewing Spirit, percentage open questions, percentage complex reflections, percentage Motivational Interviewing Adherent, (iv) therapeutic alliance total score (Table 7).

\section{Discussion}

Intervention fidelity should be improved by providing advisors with training, supervision and supporting materials [21]. Nonetheless, observed adherence to intervention content was lower than expected. Paradoxically, having detailed session content may cause a conflict between achieving an intervention that can be consistently delivered and one that can be realistically delivered. The development of the fidelity measure revealed a relatively high number of items for the intended consultation length. However, advisors were not routinely using the full time allocation, with the average duration of the consultations being a third less than the time scheduled. This suggests that health advisors were selective in delivering content. Certain elements were performed consistently, such as reviewing general progress and taking weight and waist measurements, whilst others were

Table 6 Alliance mean scores by rater and inter-rater reliability

\begin{tabular}{|c|c|c|c|c|c|}
\hline Scale items & Rater 1 Mean (SD) & Rater 2 Mean (SD) & $\operatorname{ICC}(2,2)$ & 95\% Cl Lower & 95\% Cl Upper \\
\hline 1. Supportive encouragement & $4.9(1.8)$ & $5.1(1.3)$ & 0.58 & -0.01 & 0.83 \\
\hline 2. Convey expertise & $4.1(1.5)$ & $4.5(1.0)$ & Scale not reliable ${ }^{a}$ & & \\
\hline 3. Therapist's communication style & $4.4(1.3)$ & $4.6(0.6)$ & 0.07 & -1.26 & 0.61 \\
\hline 4. Involvement & $4.8(1.4)$ & $4.8(1.1)$ & 0.73 & 0.34 & 0.89 \\
\hline 5. Warmth & $4.8(1.4)$ & $4.6(1.3)$ & 0.81 & 0.54 & 0.92 \\
\hline 6. Rapport & $4.3(1.7)$ & $4.6(1.2)$ & 0.73 & 0.35 & 0.89 \\
\hline 7. Empathy & $3.8(1.6)$ & $4.6(1.3)$ & 0.79 & 0.50 & 0.91 \\
\hline 8. Client self-discloses thoughts and feelings & $4.6(2.1)$ & $4.5(1.3)$ & 0.67 & 0.21 & 0.86 \\
\hline 9. Client expresses emotions & $2.9(1.6)$ & $2.6(1.5)$ & 0.56 & -0.07 & 0.82 \\
\hline 10. Client works actively with therapist's comments & $3.1(1.6)$ & $4.0(1.0)$ & 0.52 & -0.17 & 0.80 \\
\hline 11. Client shows confidence in therapy and therapist & $3.7(1.6)$ & $4.0(1.3)$ & 0.36 & -0.55 & 0.73 \\
\hline $\begin{array}{l}\text { 12. Client and therapist agree on the kind of changes } \\
\text { to make }\end{array}$ & $3.2(1.9)$ & $3.8(1.4)$ & 0.65 & 0.17 & 0.86 \\
\hline $\begin{array}{l}\text { 13. Client and therapist share same sense about how } \\
\text { to proceed }\end{array}$ & $3.6(1.4)$ & $3.5(1.4)$ & 0.51 & -0.19 & 0.80 \\
\hline 14. Client and therapist agree on salient themes & $4.0(1.2)$ & $3.8(0.9)$ & 0.55 & -0.09 & 0.81 \\
\hline Total score & $4.0(1.1)$ & $4.2(0.8)$ & 0.72 & 0.33 & 0.89 \\
\hline
\end{tabular}

atanders [39] 
Table 7 Comparison of consultations by participants' final weight change

\begin{tabular}{|c|c|c|c|c|c|c|}
\hline Mean (SD) score & $\begin{array}{l}\text { Lost } 5 \% \text { or more of } \\
\text { baseline weight } \\
(\mathrm{N}=11)\end{array}$ & $\begin{array}{l}\text { Did not lose } 5 \% \text { or } \\
\text { more of baseline } \\
\text { weight }(N=11)\end{array}$ & Statistic & Significance & 95\% Cl Lower & 95\% Cl Upper \\
\hline \multicolumn{7}{|l|}{ Fidelity } \\
\hline Consultation length (minutes) & $21.7(7.5)$ & $16.1(6.9)$ & $t(20)=1.8$ & $p>0.05$ & -0.81 & 11.98 \\
\hline Percentage total content & $40.3(15.1)$ & $38.9(10.6)$ & $t(20)=0.2$ & $p>0.05$ & -10.23 & 33.43 \\
\hline \multicolumn{7}{|l|}{ Motivational interviewing } \\
\hline Motivational Interviewing Spirit & $3.4(0.4)$ & $3.1(0.6)$ & $t(20)=1.3$ & $p>0.05$ & -0.18 & 0.73 \\
\hline Percentage open questions & $59.0(30.3)$ & $50.3(24.7)$ & $\mathrm{t}(20)=0.7$ & $p>0.05$ & -15.83 & 33.43 \\
\hline Percentage complex reflections & $8.2(9.5)$ & $10.4(9.1)$ & $t(20)=-0.6$ & $p>0.05$ & -10.48 & 6.06 \\
\hline $\begin{array}{l}\text { Percentage Motivational } \\
\text { Interviewing Adherent }\end{array}$ & $55.8(15.6)$ & $50.5(19.0)$ & $t(20)=0.7$ & $p>0.05$ & -10.15 & 20.75 \\
\hline \multicolumn{7}{|l|}{ Therapeutic alliance } \\
\hline Alliance total score & $4.3(0.7)$ & $3.9(1.0)$ & $\mathrm{t}(20)=1.0$ & $p>0.05$ & -0.39 & 1.01 \\
\hline
\end{tabular}

performed inconsistently, such as reviewing participants' use of information from the previous session and goal-setting. The findings indicated that advisors focused more on practical elements and education than on exploring participants' perspectives. The latter is potentially more challenging, despite the availability of time and relationship continuity. Notwithstanding the detailed guide to content, differing levels of skill are required across intervention components. This may highlight a limitation of interventions designed to be delivered by trained advisors rather than by traditionally trained health professionals, in that elements of the intervention requiring more advanced psychological consultation techniques were not delivered, despite the availability of time.

The advisors knew they were being recorded, indeed, they switched on the recording equipment, as is common in UK primary care settings. During the five-month recording period, all consultations were recorded (whether or not at the mid-point of the intervention), to 'normalise' the routine of recording, of which a fifth (22/104) were analysed. The raters reported that the advisors appeared to have a 'routine' for the consultations and that the language used (for example, in beginning the consultation and initiating the 'taking measurements' task) indicated that this was a routine familiar to the participants. This suggests that the aim of capturing a well-developed relationship and consultation routine was achieved by recording at the intervention mid-point. Whilst it cannot be ruled out, there was no evidence to suggest that the advisors were behaving differently whilst being recorded.

Higher inter-rater reliabilities were achieved for 'basic' and specific skills in motivational interviewing (e.g. whether the advisor maintains a focus on the target topic, demonstrates an empathic approach, or asks closed questions). The authors of the scale noted that it performs better for rating 'entry level' than expert therapeutic behaviours, and specifically, for measuring empathy and micro-skills (such as using open and closed questions) rather than advanced skills (such as creating a discrepancy between client values and behaviours or eliciting change talk) [32]. The findings of the present study are consistent with this. It is, however, easier to code a behaviour reliably when it is present, as behaviours which appear to meet the criteria can be scrutinised and any discrepancies between raters discussed.

The findings suggested that the advisors were operating at 'entry level' proficiency in motivational interviewing, which is consistent with the advisors' level of experience and skill. Advisors consistently demonstrated an empathic approach and maintained a focus on the topic of weight loss. This concurs with the results about fidelity, which also found the advisors to be consistently encouraging and supportive. However, more advanced therapeutic skills in motivational interviewing were not observed. This 'layering' of skills in motivational interviewing, with increasing complexity requiring considerable experience and training, is consistent with other research [24].

In terms of therapeutic alliance, higher inter-rater reliability was achieved for affective qualities of the relationship (e.g. involvement, warmth, rapport and empathy) than specific skills (e.g. client works actively with therapist's comments). Consistent with the findings from the other two measures, advisors demonstrated 'entry level' proficiency, achieving higher ratings for aspects of the quality of the interpersonal climate, such as supportive encouragement, involvement, warmth, rapport and empathy.

Overall, the findings demonstrated that certain aspects of the intervention were consistently delivered. Participants' weight was checked, information was provided, and sessions maintained a focus on the target outcome. Furthermore, these tasks were conducted in the context of a warm and supportive advisor-participant relationship. Interviews with participants in the Camden Weight Loss trial reported elsewhere revealed that the most 
valued aspects of the intervention were the relationship they formed with the advisor, followed by regularity of meetings [38].

The aim of the trial was to examine the feasibility and effectiveness of a weight management programme which was centrally organised but locally delivered in a primary care setting. Other research examining consultations in primary care in which weight management is discussed has demonstrated the importance of training health professionals in weight management interventions [18]. The results of the present study, however, highlight the importance of ongoing training and supervision. Multi-component weight management interventions comprise a spectrum of tasks and skills at varying levels of sophistication, which take time to acquire and develop.

An important determinant of intervention delivery is the congruence between the aims of the intervention and the experience and skill of the provider. One solution may be to use recorded consultations during supervision to provide feedback about fidelity and discuss strategies the advisor might use to achieve the intervention aims. In addition to providing ongoing training and supervision, another solution might be to alter the complexity of the intervention over time, as advisors' experience and skill increase.

This study had several limitations. Consultation recordings were not available for all participants in the study, as they were gathered during a five-month period and participants varied in their start date for the 12-month intervention. Recordings were also subject to the vagaries of the primary care settings, including technical failure. The present sample attended a greater number of sessions compared to others in the intervention group, as those included necessarily continued to at least session 9, and were more likely to be male, although there is no clear explanation for this (there was no gender difference in the number of sessions completed). The small sample size made it difficult to assess the impact of variation in fidelity on intervention outcome (final weight change). Nonetheless, the observed consultations appeared to provide a representative picture of the intervention as delivered in practice.

The health advisors in the study were recruited and trained as recommended by the National Health Service Health Trainers Initiative [26]. However, the study did not examine delivery of the intervention by other types of advisors, such as professionals trained in primary care or psychological interventions. Advisors with different backgrounds and experience may have delivered the intervention differently.

\section{Conclusions}

The results of randomised controlled trials and the effectiveness of complex interventions addressing behaviour change are dependent on the fidelity of the intervention delivered. Obesity statistics indicate that weight management interventions will continue to be required for the foreseeable future, emphasising the need for effective intervention delivery. This study has demonstrated that an independent process evaluation can identify the components of a complex intervention which are and are not reliably delivered. As these interventions are complex and layered, advisors delivering such interventions require considerable support, training and ongoing supervision to support those attempting to achieve significant weight loss.

\section{Abbreviations}

CAMWEL: Camden Weight Loss; Cl: confidence interval; EG: Emma Godfrey;

GB: Gabriella Baez; ICC: intra-class correlation coefficient; KN: Kiran Nanchahal; LA: Liane Al-Baba; LN: Lorraine Noble; N: number; NHS: National Health Service; NICE: National Institute for Health and Care Excellence; NT: Nicki Thorogood; SD: standard deviation; UCL: University College London; UK: United Kingdom

\section{Funding}

Camden Primary Care Trust (NHS Camden) funded the intervention from which the data were gathered. The funding source had no role in the design or conduct of the study; collection, management, analysis or interpretation of the data and preparation, review or approval of the manuscript.

\section{Availability of data and materials}

The data used during the current study are not publicly available as they consist of audio- and video-recordings of consultations during an intervention from which individual health advisors and/or volunteers receiving the weight loss intervention might be identifiable. Confidentiality of the data was stipulated in the study protocol, as approved by the local research ethics committee.

\section{Authors' contributions}

$L N, E G, K N$ and NT conceived and designed the study, KN and NT contributed to acquisition of data, LN, EG, LA and GB contributed to analysis of the data; $L N$ drafted the article, all authors contributed to the interpretation of the data, preparation of the manuscript and have read and approved the manuscript.

\section{Ethics approval and consent to participate}

The project was approved by the London School of Hygiene and Tropical Medicine Observational/Interventions Research Ethics Committee, reference number 6356. Written consent was obtained from all participants.

\section{Consent for publication}

Not applicable.

\section{Competing interests}

The authors declare they have no competing interests.

\section{Publisher's Note}

Springer Nature remains neutral with regard to jurisdictional claims in published maps and institutional affiliations.

\section{Author details}

${ }^{1}$ UCL Medical School, University College London, Royal Free Hospital, Rowland Hill Street, NW3 2PF, London, UK. '² Department of Psychology, Institute of Psychiatry, Psychology and Neuroscience, King's College London, London, UK. ${ }^{3} \mathrm{UCL}$ Research Department of Epidemiology and Public Health, UCL, London, UK. ${ }^{4}$ Department of Social and Environmental Health Research, London School of Hygiene and Tropical Medicine, London, UK. 
Received: 19 January 2017 Accepted: 7 June 2018

\section{Published online: 10 September 2018}

\section{References}

1. The LancetUrgently needed: a framework convention for obesity control. Lancet. 2011;378(9793):741.

2. World Health Organization. Global Health Observatory $(\mathrm{GHO})$ data: Obesity 2016 http://www.who.int/gho/ncd/risk_factors/obesity_text/en/\#. Accessed 17 Jan 2017.

3. Health and Social Care Information Centre. Statistics on obesity, physical activity and diet, England; 2016. ISBN 978-1-78386-698-4.

4. Department of Health. Policy paper. 2010 to 2015 government policy: obesity and healthy eating; 2015. https:/www.gov.uk/government/publications/2010to-2015-government-policy-obesity-and-healthy-eating/2010-to-2015government-policy-obesity-and-healthy-eating. Accessed 17 Jan 2017.

5. NICE National Institute for Health and Social Care Excellence. Weight management: lifestyle services for overweight or obese adults. NICE public health guidance 53; 2014. https://www.nice.org.uk/guidance/ph53. Accessed 17 Jan 2017.

6. Buckroyd J. Psychological interventions for people with a $\mathrm{BMI} \geq 35$. In: Obesity in the UK: a psychological perspective. Obesity Working Group, Professional Practice Board, The British Psychological Society; 2011. https:// www1.bps.org.uk/system/files/Public\%20files/Policy/obesity_in_the_uk__a_ psychological_perspective.pdf. Accessed 17 Jan 2017.

7. Hartmann-Boyce J, Johns D, Aveyard P, Onakpoya I, Jebb S, Phillips D et al. Managing overweight and obese adults: update review. The clinical effectiveness of long-term weight management schemes for adults. Review 1a. University of Oxford; 2013a. https://www.nice.org.uk/guidance/ph53/ evidence/evidence-review-1a-431707933. Accessed 17 Jan 2017.

8. Hartmann-Boyce J, Johns D, Aveyard P, Onakpoya I, Jebb SA, Phillips D et al. How components of behavioural weight management programmes affect weight change. Review 1b. University of Oxford; 2013b. https://www.nice. org.uk/guidance/ph53/evidence/evidence-review-1b-431707934. Accessed 17 Jan 2017.

9. Johns D, Hartmann-Boyce J, Aveyard P, Onakpoya I, Jebb S, Phillips D et al. Weight regain after behavioural weight management programmes. Review 1c. University of Oxford; 2013a. https://www.nice.org.uk/guidance/ph53/ evidence/evidence-review-1c-431707935. Accessed 17 Jan 2017.

10. Johns D, Hartmann-Boyce J, Aveyard P, Lewis A, Jebb SA, Phillips D et al. Managing overweight and obese adults: evidence review. Review 2. University of Oxford; 2013b. https://www.nice.org.uk/guidance/ph53/ evidence/evidence-review-2-431707936. Accessed 17 Jan 2017.

11. Marchant D. Exercise for obese individuals. In obesity in the UK: a psychological perspective. Obesity working group, professional practice board, the British psychological Society; 2011. https://www1.bps.org.uk/ system/files/Public\%20files/Policy/obesity_in_the_uk_-_a_psychological_ perspective.pdf. Accessed 17 Jan 2017.

12. Sniehotta FF, Simpson SA, Greaves CJ. Weight loss maintenance: an agenda for health psychology. Br J Health Psychol. 2014;19(3):459-64.

13. Jeffery RW, Epstein LH, Wilson GT, Drewnowski A, Stunkard AJ, Wing RR. Long-term maintenance of weight loss: current status. Health Psychol. 2000; 19(15):5-16.

14. Miller W, Rollnick S. Motivational interviewing: preparing people for change. 2nd ed. New York: Guilford Press; 2002.

15. Burke BL, Arkowitz H, Menchola M. The efficacy of motivational interviewing: a meta-analysis of controlled clinical trials. J Consult Clin Psychol. 2003;71(5):843-61.

16. Armstrong MJ, Mottershead TA, Ronksley PE, Sigal RJ, Campbell TS, Hemmelgarn BR. Motivational interviewing to improve weight loss in overweight and/or obese patients: a systematic review and meta-analysis of randomized controlled trials. Obes Rev. 2011;12(9):709-23.

17. van Dorsten B. The use of motivational interviewing in weight loss. Current Diabetes Reports. 2007;7(5):386-90

18. Cox ME, Yancy WS, Coffman CJ, Østbye T, Tulsky JA, Alexander SC, et al. Effects of counseling techniques on patients' weight-related attitudes and behaviors in a primary care clinic. Patient Educ Couns. 2011;85(3):363-8.

19. Wampold BE. How important are the common factors in psychotherapy? An update. World Psychiatry. 2015;14(3):270-7.

20. Baldwin SA, Wampold BE, Imel ZE. Untangling the alliance-outcome correlation: exploring the relative importance of therapist and patient variability in the alliance. J Consult Clin Psychol. 2007;75(6):842-52.
21. Dane AV, Schneider BH. Program integrity in primary and early secondary prevention: are implementation effects out of control? Clin Psychol Rev. 1998;18(1):23-45.

22. Sánchez V, Steckler A, Nitirat P, Hallfors D, Cho H, Brodish P. Fidelity of implementation in a treatment effectiveness trial of reconnecting youth. Health Educ Res. 2007;22(1):95-107.

23. Appel LJ, Clark JM, Yeh HC, Wang NY, Coughlin JW, Daumit G, et al. Comparative effectiveness of weight-loss interventions in clinical practice. $\mathrm{N}$ Engl J Med. 2011;365(21):1959-68.

24. van Eijk-Hustings YJ, Daemen L, Schaper NC, Vrijhoef HJ. Implementation of motivational interviewing in a diabetes care management initiative in the Netherlands. Patient Educ Couns. 2011;84(1):10-5.

25. Nanchahal K, Power T, Holdsworth E, Hession M, Sorhaindo A, Griffiths U, et al. A pragmatic randomised controlled trial in primary care of the Camden weight loss (CAMWEL) programme. BMJ Open. 2012;2(3):e000793.

26. Michie S, Rumsey N, Fussell A, Hardeman W, Johnston M, Newman S et al. Improving health: changing behaviour. NHS health trainer handbook. London: Department of Health Publications (Best Practice Guidance: Gateway Ref 9721), 2008. http://eprints.uwe.ac.uk/12057. Accessed 17 Jan 2017.

27. NICE National Institute for Health and Social Care Excellence. Obesity prevention. Clinical guideline CG43; 2006. https://www.nice.org.uk/ Guidance/cg43. Accessed 17 Jan 2017.

28. Bandura A. Social foundations of thought and action: a social cognitive theory. Englewood Cliffs, NJ: Prentice-Hall; 1986.

29. Locke EA. Latham GP. A theory of goal setting and task performance. Englewood Cliffs, NJ: Prentice-Hall; 1990.

30. Alemi F, Neuhauser D, Ardito S, Headrick L, Moore S, Hekelman F, et al. Continuous self-improvement: systems thinking in a personal context. Jt Comm J Quality and Patient Saf. 2000;26(2):74-86.

31. Moyers TB, Martin T, Manuel JK, Miller WR, Ernst D. Revised global scales: Motivational interviewing treatment integrity 3.1. 1 (MITI 3.1. 1). Unpublished manuscript, University of New Mexico, Albuquerque, NM; 2010 http://casaa.unm.edu/download/miti3 1.pdf. Accessed 17 Jan 2017.

32. Moyers TB, Martin T, Manuel JK, Hendrickson SM, Miller WR. Assessing competence in the use of motivational interviewing. J Subst Abus Treat. 2005;28(1):19-26.

33. Carels RA, Darby L, Cacciapaglia HM, Konrad K, Coit C, Harper J, et al. Using motivational interviewing as a supplement to obesity treatment: a steppedcare approach. Health Psychol. 2007;26(3):369-74.

34. Godfrey E, Chalder T, Ridsdale L, Seed P, Ogden J. Investigating the active ingredients of cognitive behaviour therapy and counselling for patients with chronic fatigue in primary care: developing a new process measure to assess treatment fidelity and predict outcome. Br J Clin Psychol. 2007;46(3): 253-72.

35. Fleiss $J$, Levin, Paik MC. The measure of inter-rater agreement. In: Fleiss JL, Levin B, Paik MC, Statistical methods for rates and proportions, New Jersey: John Wiley \& Sons; 2013. p. 598-626.

36. Uebersax J. Raw agreement indices; 2014. http://www.john-uebersax.com/ stat/raw.htm. Accessed 17 Jan 2017.

37. Cicchetti DV. Guidelines, criteria, and rules of thumb for evaluating normed and standardized assessment instruments in psychology. Psychol Assess. 1994;(4):284-90

38. Holdsworth E, Thorogood N, Sorhaindo A, Nanchahal K. A qualitative study of participant engagement with a weight loss intervention. Health Promot Pract. 2016;1524839916659847

39. Landers R. Computing intra-class correlations as estimates of inter-rater reliability in SPSS. The Winnower, 2015;3:e143518.81744. https:// thewinnower.com/papers/1113-computing-intraclass-correlations-icc-asestimates-of-interrater-reliability-in-spss. Accessed 17 Jan 2017. 